\title{
Effects of Heat Input in Laser Welding of Dissimilar Galvanized Steel to Aluminium Alloy
}

\author{
Celalettin Yuce, Fatih Karpat, Nurettin Yavuz \\ Department of Mechanical Engineering, Uludag University \\ Bursa, Turkey \\ cyuce@uludag.edu.tr
}

\begin{abstract}
The hybrid structures of aluminum-steel have been increasingly used for body-in-white constructions in order to reduce weight and cost. Obtaining acceptable joints between steel and aluminum required a better understanding of welding metallurgy and their effects on the resultant mechanical properties as well as the microstructure of the joints. In this research, laser welding of galvanized steel and aluminum alloy in an overlapped configuration was carried out. The influence of heat input on the weld bead dimension, microstructural and mechanical properties of the joints was studied. The experimental results showed that the penetration depth and weld width increased with the increase of heat input level. However, in order to limit IMC layer thickness and hardness at the surface of the weld seam and aluminum alloy, iron to aluminum dilution should be restricted by limiting the penetration depth. At lower heat input levels, less brittle IMC formation was formed. Consequently, with limited penetration depths at low heat input levels, tensile shear load increased, with failures located in the interface of the joints.
\end{abstract}

Keywords: Laser Welding, Aluminium-Steel, Heat Input, Weld Bead Dimension.

\section{Introduction}

Recently, there has been an increasing demand for lightweight and high strength materials in the automotive and aerospace industries due to fuel consumption and reduction of carbon emissions. Aluminum alloys are currently the most widely used light alloy in these industrial sectors due to unique characteristics such as low density, good formability, recyclability, and corrosion resistance. As well as, galvanized high strength steels have satisfied the current automobile industry requirements by ensuring excellent mechanical properties, low cost, high strength, low yield to tensile ratio and corrosion resistance. Therefore, replacing a limited number of parts by a combination of hybrid steel-aluminum structures may be a useful alternative for getting lightweight and cost-effective vehicles.

There are several difficulties arising mainly from dissimilarities in mechanical and physical properties of the aluminum and steel such as thermal expansion coefficient, conductivity and melting points [1]. Compared to traditional welding techniques, laser welding has many advantages, such as high power density, deep penetration depth, a narrower heat-affected zone, lower heat input applied per unit length [2]. However, there are some technical issues that need to be addressed when joining aluminum to steel. One of the most important phenomena for aluminum-steel joints is the formation of brittle intermetallic compounds (IMC) such as $\mathrm{FeAl}, \mathrm{Fe}_{2} \mathrm{Al}_{5}$, and $\mathrm{FeAl}_{3}$ which significantly deteriorates the joint performance by forming cracks. Two types of IMCs were reported to have been formed in laser welding of steel to aluminum, Fe-rich, and Al-rich. It has been stated that the Al-rich IMCs were much more brittle than the Fe-rich IMCs, and to have better weld mechanical properties, the formation of Al-rich IMCs should be limited [3]. It was reported that the critical thickness of the IMCs should be below $10 \mu \mathrm{m}$ in order to achieve a high strength joint in laser welded dissimilar aluminum-steel joints [4].

Several studies were carried out on laser welding of dissimilar steel to the aluminum alloy in the literature. Fan et al. [5] studied the effect of the thermal cycle on the IMC formation during pulsed laser welding of the overlapped steel aluminum joint. They concluded that peak temperature and cooling time were increasing with the rising laser power, while the IMC layer thickness was increasing nonlinearly. Torkamany et al. [6] investigated the effect of laser power, pulse duration and overlapping factor on the IMC formation and stated that increasing pulse duration caused more heat input per unit length. Yang et al. [7] used pulsed laser welding in joining steel to aluminum and stated that at high penetration depth joints Al-rich IMCs were formed which initiate microcracks and deteriorate the mechanical properties of joint. Lahdo et al. [8] investigated the influence of laser spot size on the weld dimension and appearance of the cracks laser welded thick steel-aluminium joints. 
They stated that the crack length was increased with higher energy inputs. Wang et al. [9] investigated microstructure and mechanical properties of laser welded overlap configuration joints with and without foil interlayer. They stated that the thickness of IMC layer could be reduced to $2 \mu \mathrm{m}$ by using the A15Si foil interlayer and with foil interlayer maximum tensile load reached about $230 \mathrm{~N} / \mathrm{mm}$. Meco et al. [10,11] used laser welding to join aluminum alloys to steel on defocused mode laser weld in this way; they could control the heat input and obtained control of the IMC formation.

Although welding of aluminium alloy to steel is considered as a comparatively complex laser welding process in comparison with similar material joining, besides this laser welding of galvanized steel to aluminium alloys also have several problems such as due to the boiling point of zinc coating is under the melting point of $\mathrm{Fe}$ and the boiling point of aluminium. This thermal differences caused an unstable melt pool resulting from zinc vaporization [12]. For eliminating these problems, several methods have been applied including using a bifocal hybrid laser system, drilling vent holes along the weld line and forming a gap between welding materials to allow zinc vapor to escape from the keyhole [13]. Chen et al. [12] investigated the characteristics of laser welded $\mathrm{Zn}$-coated steel and aluminum alloy joints as stitching. They studied the influences of the laser process parameters on the weld quality. A variety of studies were carried out on laser welding of galvanized steels to al alloys in a lap joint configuration. Kouadri-David [14] investigated the effect of zinc layer on the mechanical properties of laser welded dissimilar aluminum-steel joints. They obtained nearly $190 \mathrm{MPa}$ shear strengths under the controlled laser operating parameters and optimized penetration depth which must be limited to $600 \mu \mathrm{m}$. Ma et al [15] developed a two-pass laser welding procedure for the dissimilar joining of zero-gap overlapped galvanized steel to $\mathrm{Al}$ alloy. In this procedure first, pass used for melting zinc coating between the aluminium and steel interface. They obtained partially penetrated welds with no blowholes and spatter. The purpose of this study is to investigate the effect of heat input on the weld bead dimension, mechanical properties and microstructure of the zero-gap overlapped galvanized steel to Al alloy joints. Metallurgical characterization, hardness measurement, and tensile shear testing were carried out in order to evaluate the weld quality obtained by different heat input levels. A correlation has been established between penetration depth, IMC layer thickness and tensile load.

\section{Experimental Procedure}

The DP600 steel having a thickness of $0.8 \mathrm{~mm}$ with a galvanized coating and aluminum alloy 6082-T6 was selected in the study. Their nominal chemical compositions are listed in Table 1.

Table 1. The chemical composition of AA6082-T6 and galvanized DP600 steel, wt\%.

\begin{tabular}{|c|c|c|c|c|c|c|c|c|}
\hline & $\mathbf{C}$ & $\mathbf{M n}$ & $\mathbf{S i}$ & $\mathbf{A l}$ & $\mathbf{C r}$ & $\mathbf{M o}$ & $\mathbf{M g}$ & $\mathbf{F e}$ \\
\hline DP600 & 0.07 & 1.4 & 0.48 & 0.04 & 0.21 & 0.2 & - & Base \\
\hline AA6082 & - & 1 & 1.31 & Base & 0.25 & - & 1.2 & 0.5 \\
\hline
\end{tabular}

Each sheet was prepared with the dimensions of $150 \mathrm{~mm}$ in length, $80 \mathrm{~mm}$ in width. During the welding process, the gap between two sheets was kept tight. In order to reduce possible residues, strict cleaning was applied before welding with appropriate chemical solutions. IPG Ytterbium fiber laser attached to a Kuga robotic arm was used for welding experiments. During the fiber laser welding process, no shielding gas was used.

This work aimed at investigating the effect of heat input on the weld bead dimensions, IMC phases and thicknesses, and tensile shear load of the joint. The dimensions of the weld bead measured through metallographic examination. Penetration depth was measured as the weld penetration depth in the aluminum alloy, while weld width was defined as the weld width in the joining plane.

At the metallographic examination stage of the study, the samples were cut from the weld cross section using electrical discharge cutting machine, then mounted in bakelite, ground and polished with diamond paste. Two different etching procedure was conducted to reveal the grain boundaries. In the first stage of the etching, Nital solution was used for obtaining the grain boundaries of the steel. Etching with Keller's reagent was used to reveal the aluminum. Then, samples were analyzed for microstructural changes, weld seam dimensions and possible weld defects using an optic microscope with digital image analysis system and scanning electron microscope (SEM) with energy dispersive spectroscopy (EDS). Microhardness 
measurements were performed by Vickers microhardness test machine with the $15 \mathrm{~s}$ duration and 50 gf to evaluate microhardness distribution of the welded joints and IMC layers. Tensile samples were machined from the perpendicular to the welding direction in accordance with ASTM standard. Tensile tests were performed with a constant crosshead speed of $2 \mathrm{~mm} / \mathrm{min}$. Furthermore, the failed samples surface examined for determining the failure characteristic of the joints.

\section{Results and Discussions}

In this work, prior experiments were done to achieve appropriate dissimilar joints. Prior experiment results showed that there was no bond at below a certain heat input level. Further for higher levels of heat input level, there was excessive heat input, and cutting of the sheets was observed. So, then the experiments were conducted using primarily results and the heat input levels were chosen between the 28,5 and $37.5 \mathrm{~J} / \mathrm{mm}$ range. The variation of the heat input was operated by varying the speed while retaining other process parameters.

The corresponding cross sections of laser welded dissimilar joints with varied heat input were shown in Fig. 1. At the equal laser power levels, increasing the speed of the welding resulted in low heat input and consequently lower penetration depth in aluminum sheet. However, due to the keyhole instabilities or variable gaps, some penetration inconsistencies observed at the same process parameters but mostly similar depths were obtained. Usually, all the dimensions of the weld bead (penetration depth and weld width), decreased with the decreasing the heat input. Due to the less molten metal, the weld bead became shallow and narrow. As Figs. 1(a)-(f) demonstrate, the increase of heat input, increased amount of materials was molten during the process. Therefore, the dimensions of the weld bead enlarged with the higher heat input. This result was similar to another study in the literature.

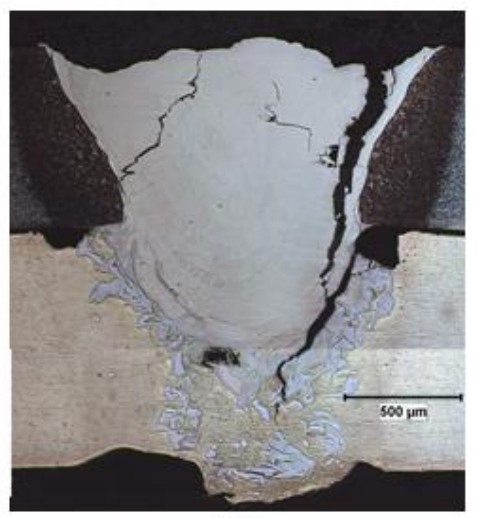

(a)

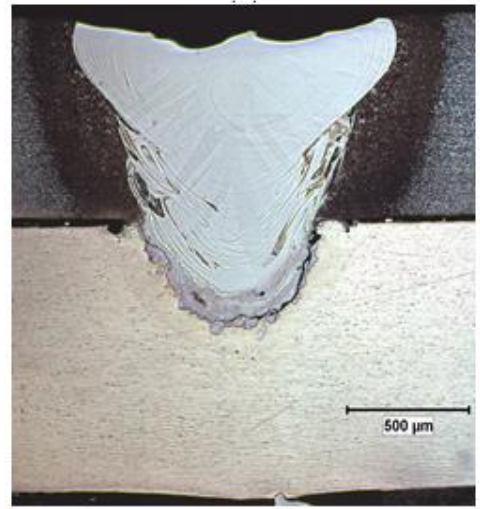

(d)

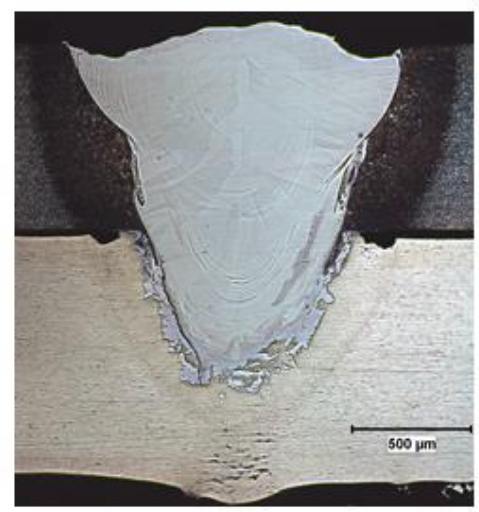

(b)

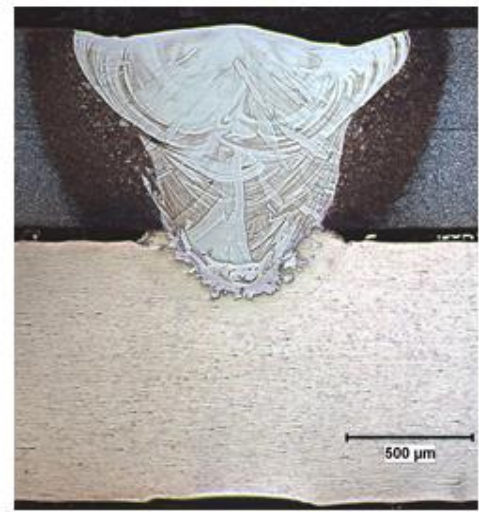

(e)

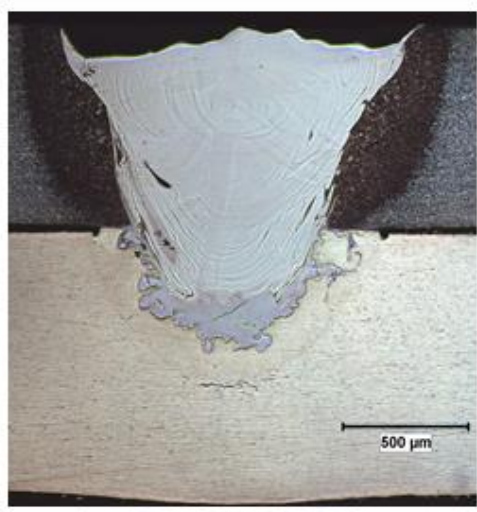

(c)

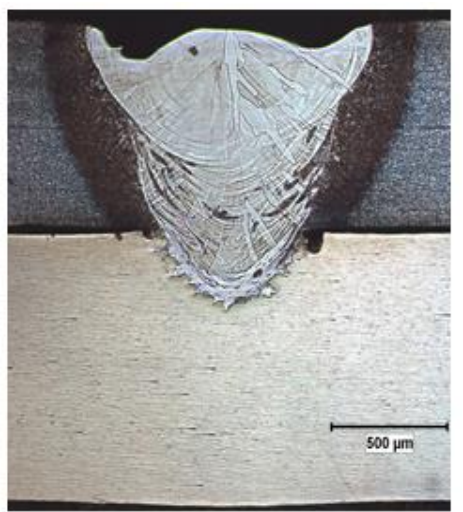

(f)

Fig. 1: The weld cross sections acquired at different heat input levels (a) $37.5 \mathrm{~J} / \mathrm{mm}$, (b) $35.3 \mathrm{~J} / \mathrm{mm}$ (c) $33.3 \mathrm{~J} / \mathrm{mm}$, (d) $31.6 \mathrm{~J} / \mathrm{mm}$, (e) 30 $\mathrm{J} / \mathrm{mm}$, (f) $28.5 \mathrm{~J} / \mathrm{mm}$. 
Fig. 2 showed the results concerning penetration depth and weld width depending on the heat input levels. There was a proper correlation between penetration depth, and heat input was obtained. Depending on the heat input level, maximum $603.5 \mu \mathrm{m}$ and $1030 \mu \mathrm{m}$ maximum penetration depth and wed width were measured, respectively. Minimum weld width and penetration depth were obtained at a heat input value of $28 \mathrm{~J} / \mathrm{mm}$, which were $565.9 \mu \mathrm{m}$ and $212 \mu \mathrm{m}$ respectively.

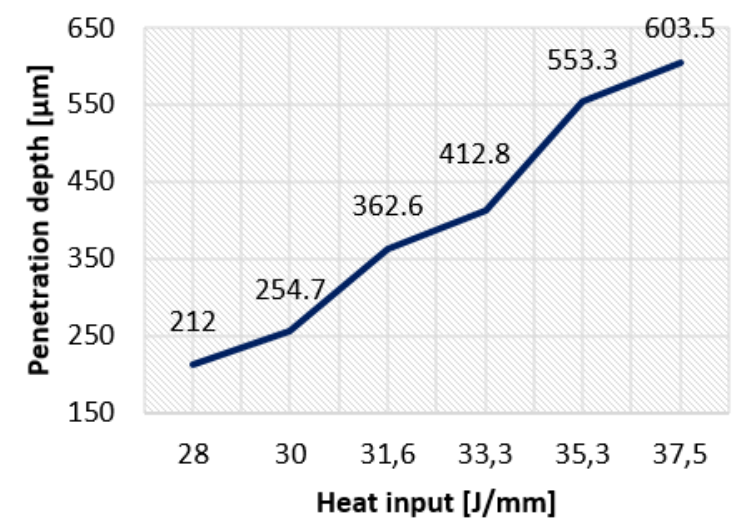

(a)

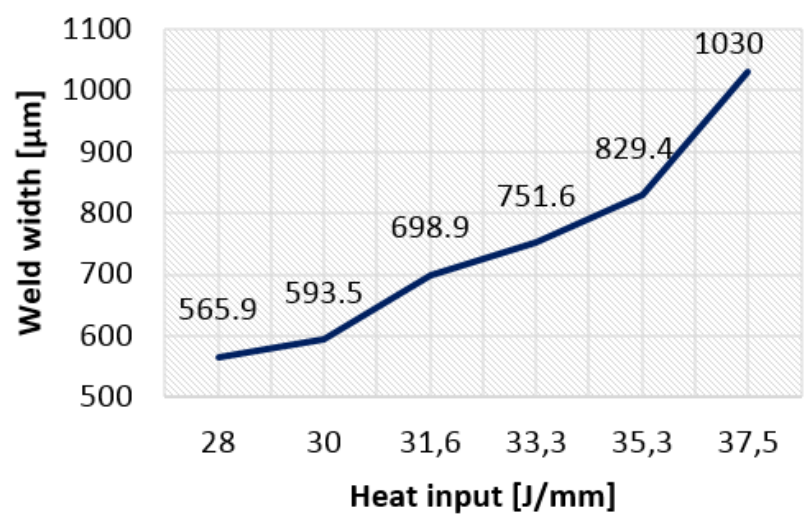

(b)

Fig. 2: Effect of heat input on the weld bead dimensions (a) penetration depth and (b) weld width.

Optical micrograph views of the specimens at two different heat inputs were shown in Fig.3. In laser welding of steel to aluminum, a higher heat input results in a lower cooling rate, causing a longer time for the formation and thickness of the IMC layer. At high heat input levels, the aluminum content within the weld seam increases due to the higher penetration depths and weld widths depending on melt flow. When the heat input was set $33.3 \mathrm{~J} / \mathrm{mm}$ the obtained penetration depth was $412.8 \mu \mathrm{m}$. In this situation, the thickness of the Al-Rich IMC layer was measured as overall $120 \mu \mathrm{m}$ (Fig. 3a). At lower heat input and penetration depth, the thickness of Al-Rich IMC layer was measured as overall $20 \mu \mathrm{m}$ (Fig. 3b).

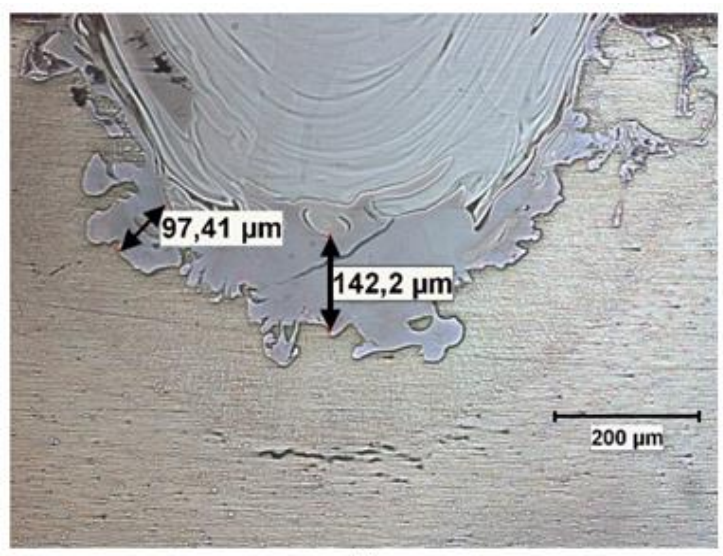

(a)

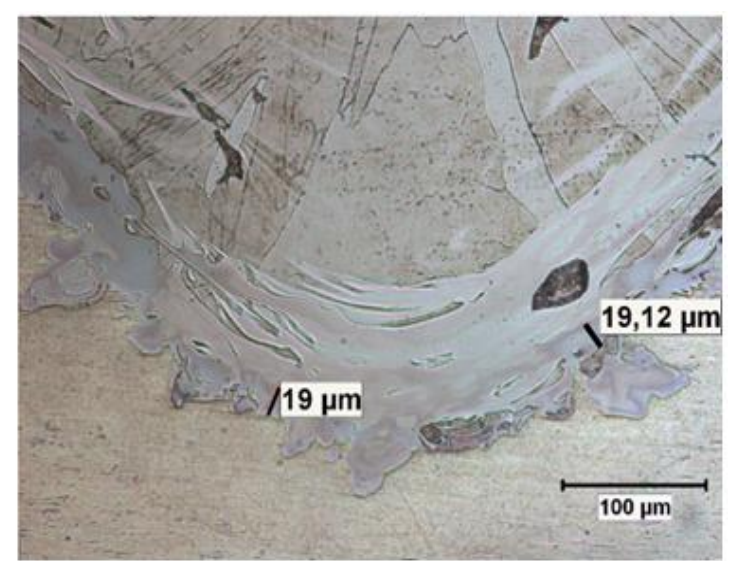

(b)

Fig. 3: Optical micrograph views of the IMC layers for different penetration depths (a) $412.8 \mu \mathrm{m}$ and (b) $212 \mu \mathrm{m}$.

During the steel to the aluminum welding process, at higher heat input levels, tended to generate more cracks in the weld. These cracks are sometimes propagating along weld-aluminum interfaces. Optical micrograph views of the specimens with several heat input levels were shown in Fig. 4. Fig. 4a showed cracks located weld-aluminum interfaces at the bottom of the weld. These cracks were evidenced for penetration above $350 \mu \mathrm{m}$. And these cracks are sometimes propagating along weld- aluminum interfaces (Fig. 4b). Under the low heat input parameter, the welds without cracks, inner pores and blowholes were obtained. 


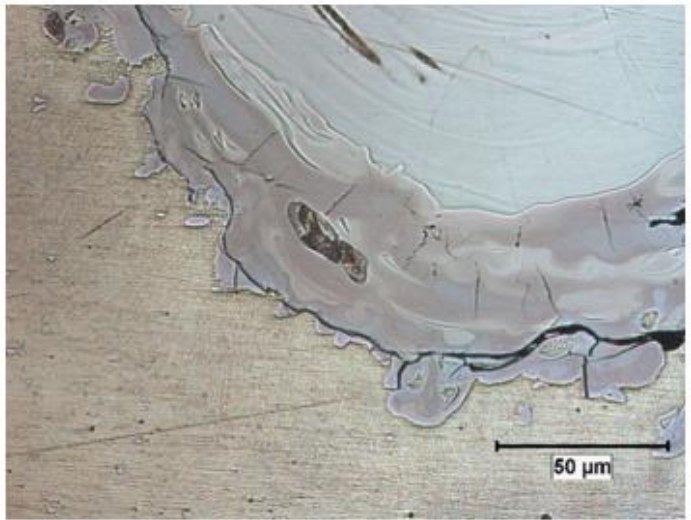

(a)

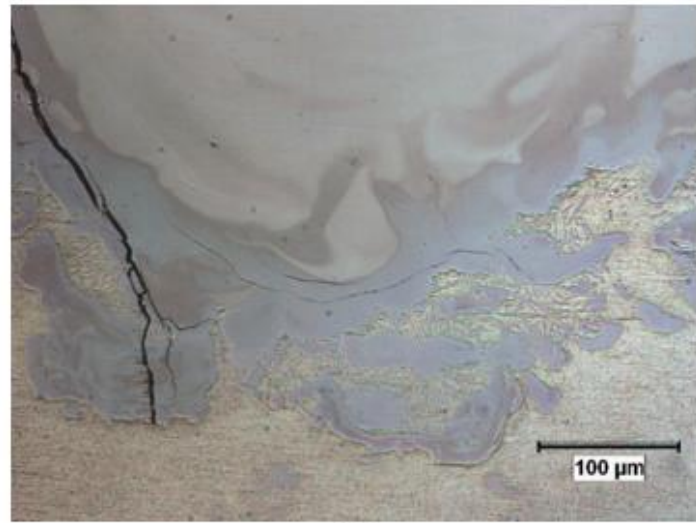

(b)

Fig. 4: Optical micrograph views of the crack locations for varying heat input levels (a) $31.6 \mathrm{~J} / \mathrm{mm}$ and (b) $35.3 \mathrm{~J} / \mathrm{mm}$.

The EDS analysis was used to acquire the atomic percent of the iron and aluminum in the weld cross sections. The IMC phases were determined by a comparison of the iron and aluminum atomic percent concerning the information from the literature [11]. The effect of the heat input and penetration depth on the formation and thickness of different IMC layers was studied. Fig. 5a showed the SEM images of high heat input $(33.3 \mathrm{~J} / \mathrm{mm})$ and high penetration depth $(412.8 \mu \mathrm{m})$ joint. As shown in Fig. 5a, according to results of the EDS analysis, fusion zone had the average composition of $13.81 \%$ aluminum, and $76.48 \% \mathrm{Fe}$. The aluminum composition was found to increase the depth of the weld seam. According to the EDS results, for the sample with heat input $33.3 \mathrm{~J} / \mathrm{mm}$, the iron-rich IMCs $\left(\mathrm{Fe}_{3} \mathrm{Al}, \mathrm{FeAl}\right)$ was generated on the weld bead and $\mathrm{Al}$-rich IMCs $\left(\mathrm{FeAl}_{2}, \mathrm{Fe}_{2} \mathrm{Al}_{5}\right)$ were generated along the weld bead boundary in the aluminum sheet. There was also a micro crack observed (Fig.5a). According to EDS analysis results, $\mathrm{Fe}_{2} \mathrm{Al}_{5}$ (Fe: 29 at \% and $\mathrm{Al}: 58$ at \%) was detected near this crack. Moreover, the hardness at this region was found nearly 1144 Vickers. This was most brittle and the hardest phase of the $\mathrm{Fe}-\mathrm{Al}$ IMCs for this two sample.

In low heat input level $(28.5 \mathrm{~J} / \mathrm{mm})$ joint, not only heat input but also the penetration depth $(212 \mu \mathrm{m})$, weld width $(565.9$ $\mu \mathrm{m})$ the fusion zone and boundary morphology was changed, as illustrated in Fig. 5b. There was no Al-Rich IMC along the weld bead boundary. According to EDS results, maximum 35\% Al content was observed. This kind of IMC phases is less brittle than Al-Rich IMC layers ( $\left.\mathrm{Fe}_{3} \mathrm{Al}, \mathrm{FeAl}\right)$. As a result, aluminum content and consequently brittle Al-Rich IMC layer at the weld seam and boundary increased with higher heat input, due to the higher penetration depth and weld widths.

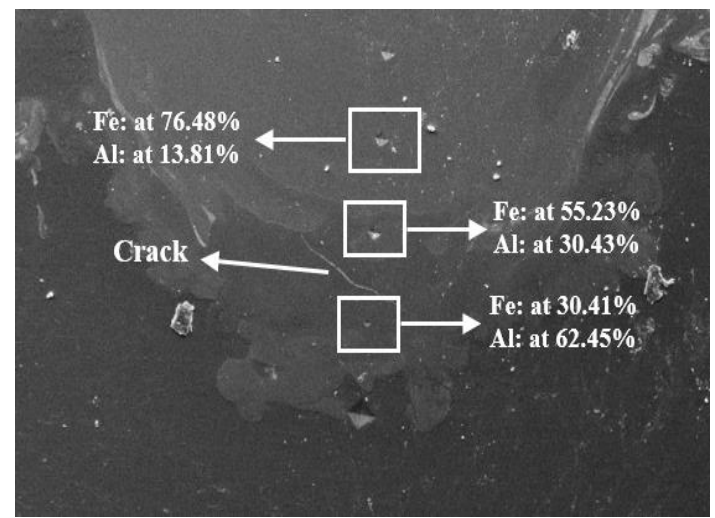

(a)

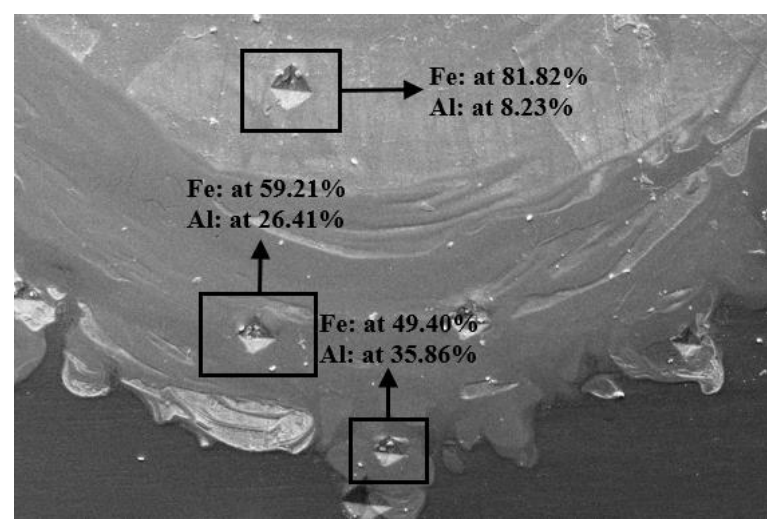

(b)

Fig. 5: SEM images with points of the EDS analysis results (a) $33.3 \mathrm{j} / \mathrm{mm}$ and (b) $28,5 \mathrm{j} / \mathrm{mm}$.

The penetration depth and weld width of the joints increase with increasing heat input. Besides these result also as a consequence, the ratio of aluminum to iron in the weld pool also increases with increasing heat input. As a result of an increasing, the aluminum concentration in the fusion zone the formation of intermetallic phases also increases, especially in 
the contact area between the bottom parts of the fusion zone. Also, cracks occurred in the border of the weld pool at high heat input levels. These cracks caused complete separation of materials in the weld zone, Thereby; it has been found that the tensile shear load of the dissimilar joints at high heat input levels were reduced. On the other hand, accordingly, prior experiments reduce heat input too small values linear energy was impossible for forming a complete weld. Thus, the heat input should be reduced as much as possible until insufficient good weld shape. Fig. 6 showed tensile shear load strength versus heat input. At highest heat input level $(37.5 \mathrm{~J} / \mathrm{mm})$, maximum penetration depth was obtained and consequently, minimum tensile shear load recorded.

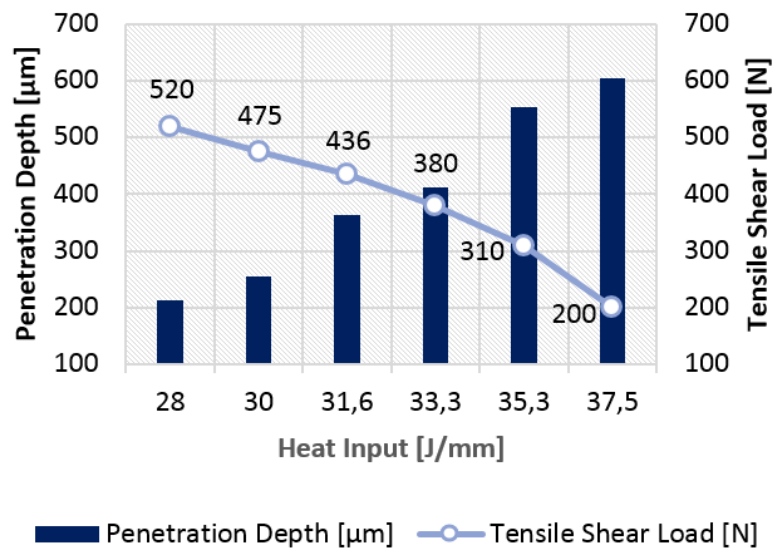

Fig. 6: Overall tensile shear load depending on the heat input and penetration depth.

In order to determine a correlation between the chemical composition and the hardness, the hardness distribution profiles along the weld bead for the different heat input levels, the Vickers hardness measurements in directions of transversal and vertical in the weld zone and along the IMC layers were carried out. The results of these tests showed that the increase of the hardness from the base metal towards the weld bead center was observed at both the aluminum and steel sides. In the weld bead, at the aluminum level, the microhardness was around 350 Vickers for a sample that had a maximum tensile shear load. At steel levels, this hardness was less than 350 Vickers. This hardness on the aluminum side can be clarified by the higher aluminum concentration at the bottom of the weld seam.

\section{Conclusion}

In this investigation, dissimilar galvanized DP600 steel and AA6082-T6 aluminum alloys in zero-gap configuration were welded using fiber laser welding process. The weld cross sections were investigated using metallographic analysis to determine the weld bead geometry, microstructure, and possible welding defects. SEM-EDS was used to determine the chemical composition, while tensile shear load and microhardness tests characterize the mechanical properties. The influence of the heat input on the penetration depth, weld width and mechanical properties of the dissimilar joints presented.

According to the examination results, the penetration depth and the weld width increase with an increasing heat input level. Besides this, consequently, the ratio of the aluminum to iron in the fusion zone and aluminum-weld interface also increases with an increasing heat input and penetration depth. As a result of the EDS analysis, aluminum content and consequently brittle Al-Rich IMC layer at the weld seam and boundary increased with higher heat input, due to the higher penetration depth and weld widths. This result is consistent with the results from [6,14]. The tensile strength of the welds decreased with heat input, consequently the penetration depth. This tensile shear load result is similar with the studies [8] and [9] in the literature. The microhardness distribution of the welds showed that there was a sharp increase in the IMC layers at high heat input and penetration depth levels. There was a dependency between the penetration depth, the aluminum ratio in the weld zone and the hardness increase on the weld interfaces.

\section{References}

[1] M. Schimek, A. Springer, S. Kaierle, D. Kracht, and V. Wesling, "Laser-welded Dissimilar Steel-aluminum Seams for Automotive Lightweight Construction," Phys. Procedia, vol. 39, pp. 43-50, 2012. 
[2] M. Uchihara, "Joining technologies for automotive steel sheets," Weld. Int., vol. 25, no. 4, pp. 249-259, 2011.

[3] L. Agudo et al., "Intermetallic Fe x Al y -phases in a steel/Al-alloy fusion weld," J. Mater. Sci., vol. 42, no. 12, pp. 4205-4214, 2007.

[4] H. Ozaki and M. Kutsuna, "Dissimilar Metal Joining of Zinc Coated Steel and Aluminum Alloy by Laser Roll Welding," Weld. Process. Ch 2, p. 35, 2012.

[5] J. Fan, C. Thomy, and F. Vollertsen, "Effect of thermal cycle on the formation of intermetallic compounds in laser welding of aluminum-steel overlap joints," Phys. Procedia, vol. 12, no. PART 1, pp. 134-141, 2011.

[6] M. J. Torkamany, S. Tahamtan, and J. Sabbaghzadeh, "Dissimilar welding of carbon steel to 5754 aluminum alloy by Nd:YAG pulsed laser," Mater. Des., vol. 31, no. 1, pp. 458-465, 2010.

[7] J. Yang, Y. L. Li, and H. Zhang, "Microstructure and mechanical properties of pulsed laser welded Al/steel dissimilar joint,” Trans. Nonferrous Met. Soc. China, English Ed., vol. 26, no. 4, pp. 994-1002, 2016.

[8] R. Lahdo, A. Springer, R. Pfeifer, S. Kaierle, and L. Overmeyer, "High-power laser welding of thick steel-aluminum dissimilar joints," Phys. Procedia, vol. 83, pp. 396-405, 2016.

[9] D. Wang, H. Wang, H. Cui, and G. He, "Enhancement of the laser welded AA6061-carbon steel joints by using Al5Si intermediate layer," J. Mater. Process. Technol., vol. 237, pp. 277-285, 2016.

[10] S. Meco, G. Pardal, S. Ganguly, S. Williams, and N. McPherson, "Application of laser in seam welding of dissimilar steel to aluminium joints for thick structural components," Opt. Lasers Eng., vol. 67, pp. 22-30, 2015.

[11] S. Meco, G. Pardal, S. Ganguly, R. M. Miranda, L. Quintino, and S. Williams, "Overlap conduction laser welding of aluminium to steel," Int. J. Adv. Manuf. Technol., vol. 67, no. 1-4, pp. 647-654, 2013.

[12] H. C. Chen, A. J. Pinkerton, L. Li, Z. Liu, and A. T. Mistry, "Gap-free fibre laser welding of Zn-coated steel on Al alloy for light-weight automotive applications," Mater. Des., vol. 32, no. 2, pp. 495-504, 2011.

[13] J. Ma, F. Kong, B. Carlson, and R. Kovacevic, "Mitigating Zinc Vapor Induced Weld Defects in Laser Welding of Galvanized High-Strength Steel by Using Different Supplementary Means,” Weld. Process., pp. 117-138, 2012.

[14] A. Kouadri-David, "Study of metallurgic and mechanical properties of laser welded heterogeneous joints between DP600 galvanised steel and aluminium 6082," Mater. Des., vol. 54, pp. 184-195, 2014.

[15] J. Ma, M. Harooni, B. Carlson, and R. Kovacevic, "Dissimilar joining of galvanized high-strength steel to aluminum alloy in a zero-gap lap joint configuration by two-pass laser welding," Mater. Des., vol. 58, pp. 390-401, 2014. 